Bulgarian Academy of Sciences. Space Research and Technology Institute. Aerospace Research in Bulgaria. 30, 2018, Sofia

DOI: https://doi.org/10.3897/arb.v30.e15

\title{
THE RISK IN AEROSPACE PROJECTS
}

\author{
Nadia Marinova \\ New Bulgarian University \\ e-mail: nmarinova@nbu.bg
}

\begin{abstract}
The risk of inconsistencies in any public activity is a determining factor in the behavior of each subject. What are aerospace projects that involve large material, technological and human resources.

The first step in the risk analysis involves tabling the different stages or phases of the design system and determining the risks for each of them, whether technical, human or economic. The time at which the event occurs may significantly affect the consequences. For example, the collapse in the air traffic control system at a major airport can cause disruption to local air traffic much more than if it occurs during the week than on Sunday morning. Similarly, an accident at the chemical plant can be far more dangerous if it causes an immediate chemical reaction that generates toxic gases than in the final phase where the waste products are less dangerous.
\end{abstract}

\section{Introduction}

For engineers and managers, the main task of risk analysis (defining the stages of a mission, examining the interconnection between the parts of the system and quantifying the probability of failure) is to identify weaknesses in construction and to indicate those that contribute most - much for delay or loss. The evaluation process may even recommend ways to minimize or mitigate the risk. An example of probable risk analysis is that made for NASA by the engineering consultancy firm Packard, Lowe \& Garrick inc. in connection with the Space Shuttle's external missile accelerators. NASA engineers and management, through the qualitative performance of the analysis, conclude that fuel leaks from the three external accelerators are "unlikely" and the risk is acceptable without fully understanding the amount of risk they are taking (although the worst, one of the problems with qualitative analysis is that the subjective interpretation of words such as "probable" and "incredible" creates preconditions for mistakes in risk assessment, for example NASA uses the term "unlikely" for risks, degree from 1:250 to 1:20 000.

Probability risk analysis shows that despite the fact that the individual risk of individual leakage is negligible, there are many places where leakage is possible. In fact, there were 5 leakages in the first 24 shuttle flights, and on 28 November 1983 
the leaking fuel self-ignites when the shuttle landed and exploded after landing. Probability risk analysis shows that there is more likely to be explosion during landing than during take-off. The analysis recommends several possible ways to reduce the risk, for example, by replacing the fuel or placing explosive barriers between the different power plants.

The theoretical basis for risk analysis is the theory of probabilities and their applications in the safety and reliability of space flights. A quantified risk statement for piloted programs is the credibility of the crew. For Apollo, the probability of a safe return of the crew was 0.999 , which means a $1.10^{-3}$ risk (1 in 1000). Risk analysis uses mathematical models for estimation and forecasting. For example, in the United States, from 1965 to 1970, the maturity model MARCEP (Maintainability and Reliability Cost Effectiveness Programm) was used to optimize the distribution of operational and emergency reservations. The model optimizes the system for the minimum weight, volume, and value when reaching a definite requirement for the mission and crew safety performance.

Risk-benefit analysis is a generic concept of risk-pricing techniques and the risk, cost and benefits of alternative projects or policies included in this assessment. Like other quantitative methods, the stages of this analysis include: defining objectives and tasks of the project alternative; identification of limiters; defining the scope and limits of the analysis itself and developing effective and feasible alternatives.

The main purpose of these techniques is to give a digital expression, if possible, of the risks and benefits of a project. Calculating these parameters requires scientific methods or simulation programs to assess the probability of failure or error. Finally, a complex assessment is made by aggregating the individual assessments of the different alternatives. Conclusions should contain the results of the sensitivity analysis where each important component or parameter changes according to its effect on aggregate risk, costs and benefits.

One of the possible approaches is based on the three main stages outlined in Fig. 1, which are formulating, analyzing and interpreting the impact of alternatives and institutional and value perspectives. When formulating risk, we determine or identify the type and amount of risk we take. Methods such as: nominal group techniques are applicable here; brainstorming; the Delphi method and others. Only the elements of risk and those elements that identify the needs, limitations and alternatives associated with risk mitigation with or without technological innovations are identified. 


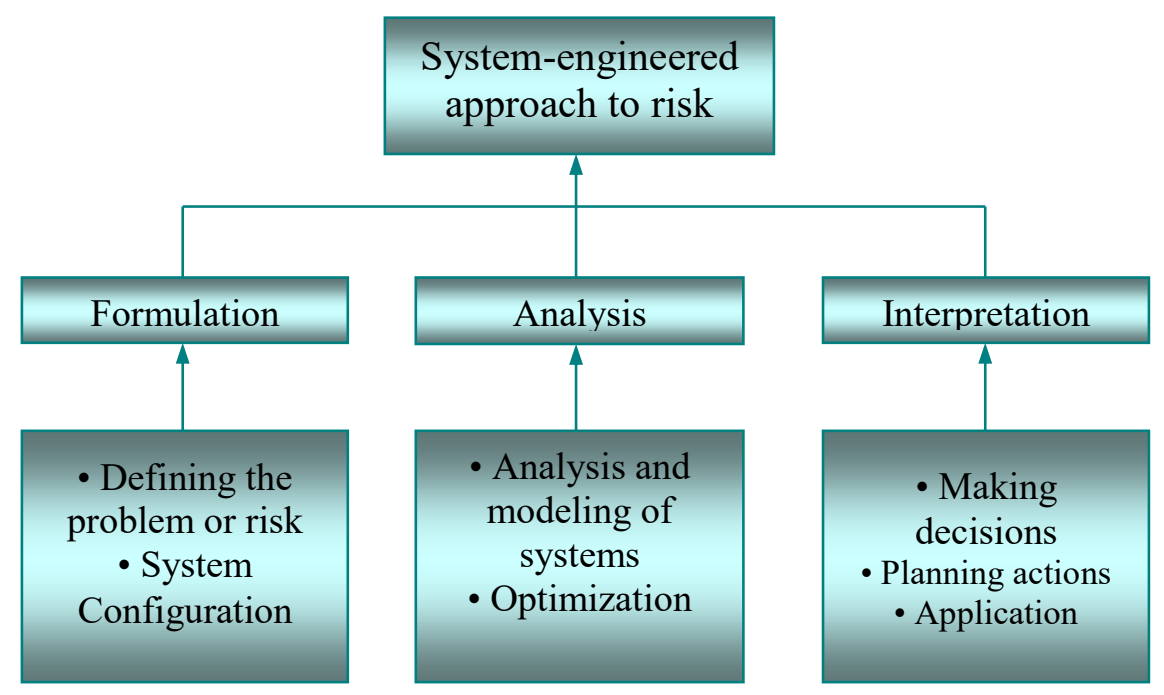

Fig. 1. Engineering System Approach to Risk Assessment

At the analysis stage, the errors, deviations and other consequences that may follow from the design and implementation of the project are predicted. This means assessing the probabilities associated with a result and the resulting fluctuations.

At the final stage, an organizational and political interpretation of the impact of the risk is given. This includes the individual and group mechanisms for the final evaluation, and then follows the decision-making process. Cost-benefit and costbenefit analyzes are best suited for this purpose. Attempts to include the results of the risk analysis in these schemes are successful. The underlying problem arises from the fact that the risk and benefits are measured with different parameters and are therefore not always compatible.

For the interpretation of the results, a risk graph is drawn up - similar to the cost-benefit ratio. Risk profiles can also be useful. For example, projects 1 and 2 are likely to generate a total profit of approximately USD 150000000 and USD 200000 000, respectively. For this reason, project 2 should be accepted by managers due to a better benefit/cost ratio. However, the data should be reviewed a little more thoroughly. Project 2 is likely to give a zero score of $15 \%$ and only $43 \%$ probability of generating a profit of $\$ 2$ million.

There is also a $20 \%$ probability that the return on project 2 will be less than project 1 . This is an additional risk if project 2 is selected.

Based on this information, managers willing to reject the risk will be willing to accept Project 1 , which has a good chance $(83 \%)$ to bring a modest profit of $\$ 150000000$, with little chance of a greater or lesser profit, i.e. project 1 has a limited standard deviation. The professional would, however, prefer Project 2, which has little chance of making more profits. 
The type of risks makes the results of the risks more transparent and thus allows the decision-maker to make choices according to his or her attitude to risk, whether it is more conservative or looser. Generally speaking, the data needed to compile the graph are limited in number, and examples from the history of such projects can easily be given. Engineers and marketing staff familiar with such projects can provide similar data. If there is no collective experience within the organization, freer or subjective assessments may be used for this purpose. There is a set of software to solve this problem.

The primary responsibility for project selection and implementation exceeds the risk assessment and lies mainly in the functions of senior management. In our opinion, notwithstanding the fact that formal analysis may imply some unexpected problems with large complex projects, it remains an academic exercise until the managers take its results seriously and ensure the proper management of the projects. Security has to be embedded in the system from the outset and good operational experience is essential to the success of any long-term risk management program.

In order to properly understand and manage the risk in certain systems, it is necessary for the managers to evaluate them at the stage of engineering projects. It is often said that the efficiency of a system can be reduced due to poor quality control, but it is not possible to improve a poor construction or design through good quality control. From the moment the project managers are in charge of making important decisions, risk assessment is one way of assessing alternatives so that their choice is more justified than isolated or, worse, repeat past errors.

\section{Possible risk assessment methods based on multiplication criteria}

Often, in the public sector, goods and services are either "complex", for example defense or space exploration, or so subsidized that their market price is an unrealistic measure of the real cost to society. Finding a way to determine the "undeformed" price of those goods and services, that is to limit the financial risk. When the analysis reaches such quantifiable parameters as security, health, quality of life, it is rarely possible to find a single variable, whose direct measurement gives an acceptable indicator. Frequently, substitutes are used. For example, the urban environmental code can be measured by an index composed of air pollution levels, noise level, traffic frequency, pedestrian density. Another index may include criminal background, fire index. At national level, it is accepted to quote unemployment rates, consumer price indices and producer prices, and the Dow Jones index. Each of these indicators is composed of multiple elements of different relative weight, which are then summed in an attributive way. Major and complex projects require more systematic and rational procedures.

The success and risk of a technical project depends on a set of criteria, the most important of which is the ability to take action to meet the project requirements. But the success and risk of the project also depend on the likelihood that the project 
will remain within the set budget and timetable, technological possibilities beyond the immediate applicability of technology, the attitude of the user to the long-term goals of the organization. In order to balance all these factors, a model of value is needed to give the decision-maker the framework to carry out these actions.

The paradigm of the analysis of each solution is shown in Fig. 2. In the process of making the decision, the person responsible for the decision must choose the "preferred" alternative of a finite set of options, so the system model can be simplified to a spreadsheet or to a dynamic mathematical simulation, and attention must be paid to the full range of economic, technological and policy aspects of the project, each alternative, along with the prevailing uncertainty, should be set on the model of the system and the result is affected.

In the paradigm of solution analysis, the results of a system give the input parameters of the value model. The output parameters are the result of the decisionmaker's preference regarding the order of the output parameters or the numerical values that show the preferences and their arrangement.

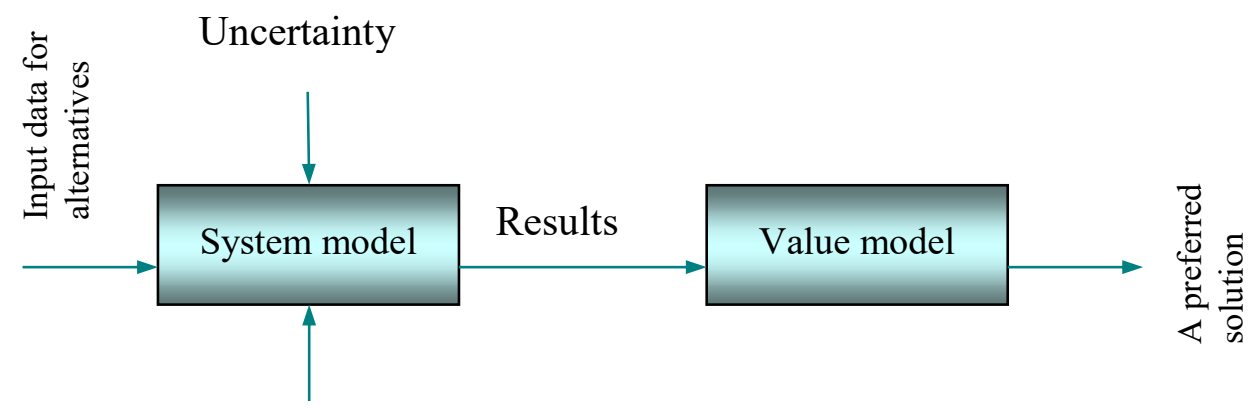

Environment

Fig. 2. Analysis of the decision

The Analytic Hierarchy Process (AHP) was developed by Thomas Saaty in order to obtain a simple yet robust methodology for multi-criteria analysis of alternatives and risks. The process can be applied to such decisions as portfolio selection, transport planning, production system design, artificial intelligence, etc. The merits of the AHR consist in the ability to structure a complex, interpersonal, multi-attribute, hierarchical problem, and to examine each level of the hierarchy by combining the results with the progress of the analysis. Comparing the individual pairs of factors (which may be alternatives, attributes or criteria depending on the context) is done by using a specific scale indicating the power a factor dominates over the others, taking into account the priority factors. The staging process can then be transformed into priority weights or alignment of alternatives. 
The AHP begins by compiling a hierarchy of goals. At the top is the wording of the problem. At the next level, in general terms, the main considerations are formulated, usually followed by a list of criteria for each consideration. Depending on how detailed the model will be, each criterion can be divided into individual parameters whose values are either evaluated or determined by experiments or measurements. The lowest level of the hierarchy contains alternatives or scenarios containing the problem being solved.

The basis of the problem is "choice of orbital mounting system" and the four main criteria are: human factor productivity, economy, design and functionality. Five alternatives include an astronaut to work outside the station, a mechanical manipulator, man-operated, a complex manipulator with computer control, a maneuverable teleworking system with a control module or a visual control and manipulator manipulator. In fact, in the analysis process, each of the Level 2 criteria is further detailed to cover the date little necessary for precise comparisons. In terms of human performance, load necessary support, team compatibility and other aspects of interaction "man-machine" included several additional factors.

Once the hierarchy is structured, local priorities must be formulated for each individual factor at a certain level, taking into account the factors directly above the survey factor. This procedure is performed by comparing factors in pairs to determine their relative weight or priority. Because this approach is primarily a qualitative comparison, it is easier to apply than Keeney and Raiffa's multi-attribute approach. This will define the functions of the preferences. Nevertheless, the theory requires the following conditions to be met in the form of axioms:

Axiom 1. If we take two alternatives (or below criterion) $i$ and $j$ from the many alternatives $A$, then the decision maker will be able to make pairwise comparison $\left(a_{i j}\right)$ when applying criterion c by a set of criteria

$$
c, a_{i j}=\frac{1}{a_{i j}} \text { for everyone } i, j \in \mathrm{A}
$$

Axiom 2. When comparing two alternatives, the decision maker never evaluates one alternative as infinitely better than the other, taking into account criterion $c$, i.e. for each.

Axiom 3. The task can be formulated in a hierarchical form.

Axiom 4. All alternatives and criteria that matter to a task can be ordered hierarchically, i.e. the intuition of the decision maker must be included (or excluded) from the structure of the criteria or alternatives.

These axioms can be used to describe the two main tasks of AHR formulating and solving a problem such as hierarchy (3 and 4) and providing assessment in the form of pairs (1 and 2). Such an assessment is an accent on results in conflicting criteria and is often too subjective. Saaty proposes to use a ratio of 1:9 
in the quantitative assessment of the decision-maker's ability to "feel" the differences between two alternatives in relation to a given criterion.

The affiliation or transitionality of items is verified by confirming the circumstance.

$$
a_{i j}=a_{i k} a_{k j} \text { for all } i, j, k
$$

In practice, decision-makers assess only "real" elements $a_{i j}$ by giving certain values so that perfect continuity of the equation is unlikely to occur. Therefore, approximation is possible elements of A can be represented as satisfying $a_{i j}=w_{j} / w_{j}$ $+e_{i j}$, where $e_{i j}$ is a factor error inconsistency of decision maker when compared with factors $i j$. If we continue the analysis one step further, one can see that the highest intrinsic value of matrix a, $\lambda_{\max }$, Udo inserts $\lambda_{\max } \geq n$, where equality means complete continuity, which leads to the determination of the sequence index:

$$
C I=\frac{\lambda_{\max }-n}{n-1}
$$

which can be used for qualitative evaluation of matrix A. To have a basis for further analysis, we compare the index $C I$ with a random matrix whose records are also randomly selected. Through Saaty's simulation, the results are as follows:

\begin{tabular}{|l|l|l|l|l|l|l|l|l|l|l|}
\hline $\mathrm{n}$ & 1 & 2 & 3 & 4 & 5 & 6 & 7 & 8 & 9 & 10 \\
\hline $\mathrm{R} 1$ & 0.00 & 0.00 & 0.58 & 0.90 & 1.12 & 1.24 & 1.32 & 1.41 & 1.45 & 1.49 \\
\hline
\end{tabular}

Here $n$ represents the parameters of the respective matrix, and $R I$ determines the arbitrary index calculated arbitrarily based on the average $C I$ for a large matrix. Thus, it is possible to determine the sequence ratio. Practice shows that the $C R$ should be less than 0.1 if we want to be completely sure of the results obtained (there is a certain degree of uncertainty in assumptions related to regression analysis). With an increase in the number of factors, less sensitive to the values of the matrix, and it can be shown that the priorities derived from the main considerations are 0.521 for human productivity, 0.205 for the economy, 0.227 for the development, 0.047 for the operation. SECTOR above the rest, probably due to the extreme importance of the program for space station itself. Coefficient of 0.045 sequence is within acceptable limits.

The next step in the analysis is to determine the global priorities for the third level factors compared to the second level factors. In the above example, the five predefined alternatives are compared with each of the key criteria. Let us assume that the necessary data are obtained and the calculations for the four comparative matrices made, the results are shown in Table 1. The first four columns represent the local priorities derived from the input data provided by the decision maker. Global 
priorities are obtained by weighing each of the values of the local priorities and then summed up.

Table 1. Local and global priorities for the choice of an orbiting system

\begin{tabular}{|c|c|c|c|c|c|}
\hline \multirow[b]{2}{*}{ Alternative } & \multicolumn{4}{|c|}{ Local priorities } & \multirow[b]{2}{*}{$\begin{array}{l}\text { Global } \\
\text { priorities }\end{array}$} \\
\hline & $\begin{array}{l}\text { Labor } \\
\text { productivity } \\
(0.521)\end{array}$ & $\begin{array}{l}\text { Economy } \\
(0.205)\end{array}$ & $\begin{array}{l}\text { Development } \\
(0.227)\end{array}$ & $\begin{array}{l}\text { Evaluation } \\
(0.047)\end{array}$ & \\
\hline 1 & 0.066 & 0.415 & 0.122 & 0.389 & 0.165 \\
\hline 2 & 0.212 & 0.309 & 0.224 & 0.151 & 0.232 \\
\hline 3 & 0.309 & 0.059 & 0.206 & 0.178 & 0.228 \\
\hline 4 & 0.170 & 0.111 & 0.197 & 0.105 & 0.161 \\
\hline 5 & 0.243 & 0.106 & 0.251 & 0.177 & 0.214 \\
\hline
\end{tabular}

1 - a cosmonaut with instruments outside the ship;

2 - a man-operated universal manipulator;

3 - a special manipulator under computer control;

4 - teleoperator with a set of manipulators;

5 - versatile sensor with touch feedback.

Global priorities at level I are derived from the following equation:

$$
W_{i}^{I}=\sum_{i=1}^{n_{I}-1} W_{i j}^{I} W_{j}^{I-1}
$$

The values listed in the last column represent the final priorities of the problem, therefore (according to the decision of the decision-maker) alternative 2 appears to be the most acceptable.

In order to complete the analysis, it is desirable to see how sensitive the results are to the changes in the assessment and to the criteria values, ie. to determine how the changes in matrix A will affect the priorities between levels, common priorities and continuity. These parameters are listed in the Exprert Choice - the most popular rule for performing AHP analyzes.

HIPRE $3+$ also have such opportunities. When there is uncertainty in the values of the individual factors, additional attributes can be defined to describe it. In general, the declared benefits of the AHP are as follows:

1. The method is easy to understand and easy to apply.

2. The construction of the target hierarchy of criteria, alternatives and attributes allows the problem to be combined and the recommended solutions.

3. Enables the use of unique techniques for quantitative evaluation and sequence of measurements.

In case of particularly important risk projects (development of a new product or business venture) requiring a long time and full dedication by a group, their implementation can be controlled by a project team. Fully recruited staff are 
committed to the project and deployed to other members of the team. The project has its own management structure and budget, but it can also be a department in the company structure.

When the project is particularly complex, protracted, risky and involves multiple individual organizations, it is advisable to give one person full control over all the elements necessary to achieve the objectives. For example, when NASA was awarded a multi-million dollar contract (Apollo Command and Service Module and Saturn's second-stage rocket) to Rockwell International, two spatially separated programs were developed. Each program was subordinate to a vice president of a department with its own production facilities and a team of specialists. This formulation applies the idea in its finished form and is called the organization of the project.

The organizational structure is related to a particular product of each organizational unit. Here the separate functions are realized within a single structural unit. This organizational structure implies duplication of resources as similar activities and processes are carried out by different structural units for different projects. The second disadvantage due to the limited lifecycle of a project is the fact that the hierarchy in the work and reporting system is constantly changing.

What are the advantages of this approach:

- strong control through specific project management;

- fast reaction;

- stimulates productivity, keeping track of schedule, reducing costs;

- staff are loyal to a particular project;

- better cooperation with other "external" organizational units;

- good customer relationship.

What are the drawbacks:

- inefficient use of resources;

- does not develop promising technologies;

- does not prepare for future orders;

- poor opportunities for exchanging technical and technological information between projects;

- minimum career opportunities for staff;

- a difficult balancing of load in the individual phases.

As an example, the project-oriented structure of the TERRA project, part of NASA's EOS program, can be mentioned. 


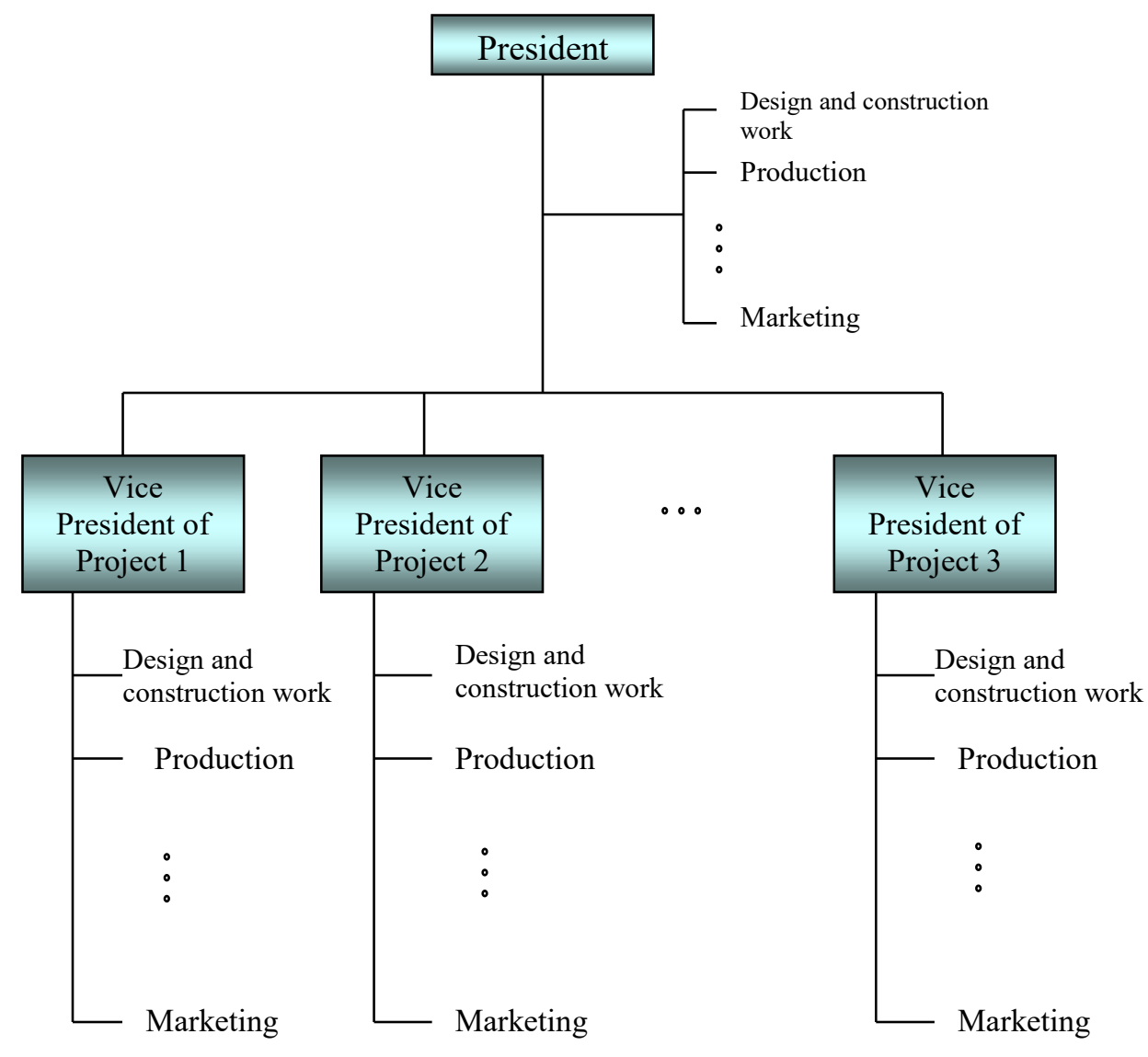

Fig. 3. Project-oriented organizational structure

\section{Conclusion}

What is the risk of identifying the project manager? The relationship between uncertainty, lack of experience and difficulties in gathering information makes project management a combination of art, science and above all logical thinking. A good project manager should be familiar with a variety of scientific disciplines and techniques. Most projects have technical, financial, marketing, and organizational subtleties that are also able to break down the best plan.

The participation of the supervisor can begin at different stages of the life cycle of a project. Some executives are engaged from the beginning, helping to identify the project, form the team, negotiate contacts. Others can start at a later stage to implement a plan they did not participate in. At a certain stage, however, most project managers face the main project activities - planning, resource finding, 
resource management, staffing, and negotiation. Especially important and perhaps most difficult for a project manager is to have a good overview of the project without losing control over the critical elements. It should eliminate the difficulties whenever decision-making is needed. Issues such as "how important the budget is compared to the timetable" or "whether additional resources need to be mobilized at the expense of budget overruns or possible deviations from the results to the extent that the project is on schedule" are typical [6] .

What basic functions and skills should the project manager have?

The Project Management Institute (US) defines six key functions pertaining to the project manager:

1) Manage the volume of the project by defining objectives and activities that need to be accomplished - with sufficient detail to facilitate understanding and implementation, as well as making adjustments when need arises;

2) Manage the human resources involved in the project;

3) Manage communications so that participating countries have sufficient information to implement the project;

4) Manage time by planning and executing schedules;

5) Manage quality so that the results of the project are satisfactory;

6) Manage costs in such a way that the project is realized at a minimum of actual costs and, if possible, within the budget.

Managing a project is a complex undertaking. Since projects are unique ventures, experience, working relationships, established procedures to guide the participants in it are not particularly useful. The project manager will have to direct many different efforts and activities to achieve the project goal. People with different qualifications and from different parts of an organization who have never worked together will be involved in the project for a different length of time. Subsidiaries who are not familiar with the organization must perform important tasks. The project may contain thousands of interrelated activities performed by staff hired by different subcontractors or by one of the leading organizations. The project manager, even under the influence of pressure and stress, has to deal effectively with changing client priorities, the fears of his executives, eliminate conflicts, and find the optimal balance between counterproductive impacts.

Generally speaking, the project manager needs enthusiasm, excitement, and desire for hard work to resist the emerging problems. Wherever possible, he / she must occupy a leading position by working with the function manager.

For these and other reasons, it is especially important that project management have effective means of identifying and conveying planned activities and their interconnection. A system of computerized planning and monitoring is needed. Network techniques such as CPM (Critical path method) or PETP (program evaluation and change technique) are extremely useful in such systems. 


\section{References}

1. Alvin, J. Silk (2006) What is marketing? Harvard Business School Publishing Co.

2. Barnes, J. G. (2000) Secrets of Customer Relationship Management, McGraw-Hill, NY.

3. Buckley, R., Caple, J. (2009). The Theory \& Practice of Training, Kogan Page.

4. Dibb, S., L. Simkin, W. M. Pride, and O.C. Ferrell (1994) Marketing - Concepts and Strategies, Houghton Mifflin Company, Boston.

5. Gargarov, Z. (2009) Economics and Market, Sofia.

6. Gray, C.F., E.W. Larson (2000) Project management. The managerial process. McGraw. Hill International Editions.

7. Khan, M.Y. (2004) Management of Financial Services, McGraw Hill.

8. Kleiner, G.B. (1997) Enterprise in an unstable economic environment: risk, strategy, security.

9. Marinova, N. (2017) International marketing, New Bulgarian University, Sofia.

10. Marinova, N. (2008) Management and leadership, New Bulgarian University, Sofia.

11. Marinova, N., A. Bliznakov, and Z. Gargarov, (2011) Ecology and economics - economy and ecology, New Bulgarian University, Sofia.

12. Marinova, N. (2012) Project management - instrument for achieving sustainable development, New Bulgarian University, Sofia.

13. Mirchev, A. (1996) Production Management, Princeps, Sofia.

\section{РИСКЬТ В АЕРОКОСМИЧЕСКИТЕ ПРОЕКТИ}

\section{Н. Маринова}

\section{Резюме}

Рискът от несполуки във всяка една обществена дейност е определящ фактор за поведението на всеки субект. Това с особена сила се отнася към такива дейности каквито са аерокосмическите проекти, в които се ангажират големи материални, технологични и човешки ресурси.

Първата стъпка при анализа на риска включва представянето в табличен вид на различните етапи или фази на проектната система и дефиниране на рисковете за всяка една от тях, били те технически, човешки или икономически. Времето, когато се проявява събитието, може съществено да повлияе на последствията. Например, срив в системата за контрол на въздушния трафик на голямо летище може да предизвика смущения в местния въздушен трафик много повече, ако стане през седмицата, отколкото в неделя сутрин. По подобен начин авария в химически завод може да бъде много поопасна, ако предизвика непосредствена химическа реакция, от която се получават токсични газове, отколкото на един краен етап, където отпадъчните продукти са по-малко опасни. 